\title{
DILEMAS SULINOS: DESAFIOS PARA A INTEGRAÇÃO DO MERCADO DO SUL.
}

\author{
SOUTHERN DILEMMAS: CHALLENGES FOR THE INTEGRATION \\ OF THE SOUTHERN MARKET.
}

\begin{abstract}
Resumo
O presente artigo almeja analisar as condições atuais para o aprofundamento das relações comerciais e políticas entre os países-membros do MERCOSUL. Partindo da compreensão que um mercado comum é uma política pública nacional e internacional, o artigo analisou a estrutura tecida através de sua historicidade para compreender seus dilemas atuais e sua institucionalidade. Através da análise de dados que nos mostram os tipos de relações comerciais estabelecidas entre os países do MERCOSUL e entre estes e outros países do globo, foi possível observar os dilemas enfrentados para o aprofundamento desse mercado comum. Conclui-se que um dos obstáculos para aprofundamento são as assimetrias econômicas e políticas entre seus membros, o que faz com que as preferências políticas do Brasil (principal membro) estejam voltadas para estratégias de um global player e não focadas na região. Enquanto global player, o interesse do Brasil é manter acordos econômicos com relação à união aduaneira do que aprofundar as raízes de um mercado comum, uma vez que isso demandaria entrega parcial de soberania para instituições supranacionais, o que sem sombra de dúvidas levaria qualquer governo nacional ao desgaste político interno. Essa conjuntura, marcada pela "imobilidade" do mercado comum, só foi possível graças ao fracasso de uma política norte-americana (fast tracks). Caso a Casa Branca tivesse ganhado o aval do Capitólio para efetuar suas políticas econômicas (fast track), o Brasil se encontraria diante de um desafio que prejudicaria sua soberania na América do Sul, criando dificuldade para este se lançar enquanto global player.
\end{abstract}

Palavras-Chave: MERCOSUL, global player, políticas públicas, fast tracks.

\section{Abstract}

This article aims to analyze the current conditions for the deepening of trade and political relations between MERCOSUL member countries. Starting from the understanding that a common market is a national and international public policy, the article analyzed the structure woven through its historicity to understand its current dilemmas and its institutionality. Through the analysis of data showing the types of commercial relations established between the MERCOSUL countries and between these countries and other countries of the world, it was possible to observe the dilemmas faced for the deepening of this common market. It is concluded that one of the obstacles to deepening is the economic and political asymmetries among its members, which makes the political 
preferences of Brazil (main member) focused on strategies of a global player and not focused on the region. As a global player, Brazil's interest is to maintain economic agreements with the customs union rather than to deepen the roots of a common market, since this would require partial surrender of sovereignty to supranational institutions, which would undoubtedly lead to any national government internal political wear and tear. This situation, marked by the "immobility" of the common market, was only possible thanks to the failure of a US policy (fast tracks). If the White House had won the Capitol's approval to pursue its fast track policies, Brazil would face a challenge that would undermine its sovereignty in South America, creating difficulty for the latter to launch as a global player.

Askeywords: MERCOSUL, global player, public policies, fast tracks.

\section{INTRODUÇÃO}

O Mercado Comum do Sul (MERCOSUL) é a expressão de uma integração regional criado em 26 de março de $1991^{1}$, que a partir da assinatura do Tratado de Assunção, estabelecia o início de uma nova configuração político e econômica na América do Sul, envolvendo diretamente países como Argentina, Brasil, Uruguai e Paraguai. Com o tratado, iniciou-se o chamado "processo de transição", que consiste na adoção de instituições provisórias até que em 1994 alcançasse as instituições definitivas que administrariam esse mercado.

De acordo com o Artigo $1^{\circ}$ do Tratado de Assunção, previa-se a livre circulação de bens, serviços e fatores produtivos através da eliminação dos direitos alfandegários e restrições não tarifárias à circulação de mercadorias. Almejava-se uma tarifa externa comum (TEC) e uma política comercial comum. Além disso, o Mercosul projetava uma coordenação de políticas macroeconômicas entre os Estados-membros, a fim de assegurar as condições adequadas de concorrência entre estes.

Com o Tratado de Assunção, inaugurou-se uma Zona Livre de Comércio (ZLC), que implica na liberalização do comércio por redução de barreiras entre os países membros. Contudo, o Mercosul não pretendia ficar restrito apenas a uma ZLC, mas que alcance através de etapas sucessivas um Mercado Comum.

Um Mercado Comum² é um fenômeno econômico e político complexo, que não se restringe apenas a circulação de bens, mas constitui níveis avançados de integração político e econômico por onde se asseguram a livre circulação de pessoas, bens, serviços e capitais, coordenação de uma política macroeconômica em que todos os países devem seguir o mesmo parâmetro de fixação da taxa de juros e de câmbio, além de uma moeda comum.

\footnotetext{
http://www.Mercosul.gov.br/index.php/saiba-mais-sobre-o-Mercosul.

2 http://www.camara.gov.br/Mercosul/blocos/introd.htm.
} 
A experiência mais conhecida para o propósito de integração regional era o da União Europeia. Seus primeiros passos podem ser reconstituídos através da criação de uma alíquota comum para cada produto, que era igual à média aritmética das alíquotas nacionais de cada país participante. (BAUMANN, 2001). Contudo, a conjuntura que cerca a integração dos países do Cone Sul, dadas as assimetrias entre os países, erige um conjunto de desafios e entraves à completa formação do bloco.

As assimetrias montam um terreno em que se instaura um problema de ação coletiva. Os acordos só podem ser firmados quando estabelecidos via consenso, sem que nenhuma das partes rejeite os pontos centrais do acordo. Uma simples dúvida em relação ao cumprimento das metas estabelecidas no acordo, por parte de algum país, pode significar a desistência dos outros países em seguir as metas estabelecidas. Soluções para esse tipo de aporia são resolvidas por questões institucionais, ou seja, arquiteta-se uma estrutura institucional "superior" (soberana) aos membros, que regulará todo o processo. O caso da união europeia se insere nessa lógica, ao passo que não podemos afirmar o mesmo para o Mercosul.

É importante compreender que a integração econômica e política entre países não é um fenômeno que se cristaliza facilmente via tratados e acordos. Inevitáveis assimetrias existentes entre os países exigem que o processo seja negociado em etapas, para que não haja prejuízo das partes envolvidas. Dentro de uma perspectiva racional (DOWNS, 1999; SILVA, 2006), nenhum país integraria um bloco econômico caso este lhe traga prejuízos (políticos, econômicos, etc.) tendo em vista sua situação antes do "contrato". As experiências que levaram à Comunidade Europeia e o próprio Mercosul confirmam esse "etapismo".

Partindo da hipótese "fracasso" da criação de um Mercado Comum (stricto sensu) entre os países do Cone Sul, nosso objetivo com esse artigo é compreender o processo de formação deste bloco enquanto uma política pública em contexto transnacional, cujos atores são Estados Nacionais ${ }^{3}$, evidenciando seus elementos de entrave para poder pensar estratégias de superação destes.

\section{ANTECEDENTES DO MERCOSUL}

$\mathrm{Na}$ década de 60 , período marcado pelas reformas que visavam desobstruir a industrialização (CEPAL, 2000), arquitetou-se Associação Latino-Americana de Livre-Comércio (ALALC), que envolvia os governos de Argentina,

3 Embora os atores aqui considerados são Estados Nacionais, reconhecemos que as políticas externas de cada podem sofrer (e sofrem) alterações conforme o partido ou presidente em. Tendo em vista que o Mercosul começa a erigir sua estrutura institucional a partir de 1991, podemos apontar, como no caso brasileiro, ao menos 4 (Collor, Itamar, Fernando Henrique Cardoso e Lula) estratégias de incorporação ao bloco. Contudo, essas particularidades não compõe esse artigo. 
Brasil, Chile e Uruguai a partir dos estudos feitos pela Comissão Econômica para a América Latina (CEPAL), vinculada a Organização das Nações Unidas (ONU). A ALALC foi firmada em 18 de fevereiro de 1960 (entrando em vigor em 10 de julho de 1961), através do Tratado de Montevidéu, onde assinaram Argentina, Bolívia, Brasil, Colômbia, Chile, Equador, México, Paraguai, Peru, Uruguai e Venezuela. Estabelecia-se assim, via Tratado, uma ZLC, mas a meta final era a criação de um Mercado Comum latino-americano. Devido à incompatibilidade do modelo de desenvolvimento dos países-membros e a rigidez dos mecanismos - que obrigava um país a estender a todos os países da ALALC preferências concedidas a outro país-membro -, os caminhos para um Mercado Comum não permaneceram abertos.

Entre os países do Cone Sul, encontramos como antecedentes históricos do Mercosul a assinatura do Acordo Tripartite Argentina-Brasil-Paraguai em 1979, que permitiu compatibilizar as cotas das hidroelétricas de Itaipu e Corpus. Esse capítulo da política internacional é marcado por divergências entre Brasil e Argentina, que disputavam a supremacia regional. Antes que o acordo tripartite fosse concretizado, o Brasil assinou com o Paraguai um acordo bilateral visando o aproveitamento hidroelétrico. O problema ocorreu porque a construção da represa ocorreu a $17 \mathrm{~km}$ da fronteira com a Argentina, próximo ao local onde esse país pretendia construir, também em parceria com o Paraguai, uma usina hidroelétrica (SILVA, 2006).

O contexto dos anos 70, segundo Bielschowsky (CEPAL 2000) era demarcado por um período em que se discutiam as reorientações dos "estilos" de desenvolvimento na direção da homogeneização social e na direção da industrialização pró-exportadora.

Diante do fracasso da ALALC em meados da década de 70, os países latino-americanos voltaram a deliberar sobre os rumos da integração regional na década de 80, período ao qual surge a Associação Latino-Americana de Integração (ALADI), que foi criada por um novo Tratado de Montevidéu (em 18 de agosto de 1980). O objetivo do novo Tratado era o prosseguimento gradual da ALALC, mas dessa vez não se determinou prazos e compromissos quantitativos pré-estabelecidos. Nessa década foram firmados dois acordos bilaterais de complementação econômica no âmbito da ALADI: O Protocolo de Expansão do Comércio (PEC) ${ }^{4}$, envolvendo Brasil e Uruguai; e o convênio Argentino-Uruguaio de Complementação Econômica (CAUCE) $)^{5}$.

http://www.aladi.org/NSFALADI/textacdos.NSF/eea2560557dco9ddo3256d2c00589172/9e2073a7740ca82 9032567eboo55eed9?OpenDocument.

http://www.aladi.org/nsfaladi/textacdos.nsf/6de70oceb7fe34a3032567f200721748/ec279aa6463935a503256 d11004f5bc3?OpenDocument. 
Outros momentos que representam uma aproximação entre Brasil e Argentina foram a assinatura, em 1985, da Declaração Conjunta Sobre Política Nuclear, demonstrando suas intenções pacíficas de cooperação em relação à agenda nuclear e os acordos do Programa de Integração e Cooperação Econômica (PICE), realizado em 1986. Por fim, em 1988, foi firmado o Tratado de Integração, Cooperação e Desenvolvimento, cujos objetivos consistia na liberalidade comercial recíproca. Não estava claro quais países integrariam esse Tratado, até que em 6 de abril daquele ano, os presidentes de Argentina, Brasil e Uruguai assinaram a Ata da Alvorada, uma decisão tripartite que previa a incorporação do Uruguai nas relações bilaterais que ocorreram entre Argentina e Brasil.

Todos esses eventos que precedem a década de 90 são importantes para percebermos que o processo de constituição do Mercosul não é marcado por decisões imediatas e decisivas, mas ocorreu por etapas envolvendo situações de conflito e consenso tendo em vista as políticas externas de cada país.

Um processo que teve início com acordos bilaterais entre Argentina e Brasil e tendo Paraguai, por vezes, como terceiro ator em cena, passou por um processo de spillover, ocasionando na incorporação de países como Uruguai e Paraguai - na condição de membros efetivos - e de diversificação da agenda de discussão que envolvia o processo de construção de um Mercado Comum do Sul, que teria até 31 de dezembro de 1994 para estar completamente conformado.

Tanto Paraguai e Uruguai consentiram com o arranjo já definido no acordo bipartite entre Argentina e Brasil. As negociações seguintes para a constituição do MERCOSUL alcançaram, em 1991 com o Tratado de Assunção, as linhas gerais do Mercado Comum, que ocorre simultaneamente ao processo de redemocratização de Argentina e Brasil.

\section{O MERCOSUL ENQUANTO POLÍTICA PÚBLICA TRANSNACIONAL}

Conceituando políticas públicas através de uma definição minimalista de tudo aquilo que o governo faz ou deixa de fazer (DYE, 2009), abrimos algumas possibilidades de compreender o fenômeno do Mercosul através do repertório conceitual desse campo (políticas públicas). Dessa forma, a análise deste objeto é passível de ser compreendida na circunscrição das estratégias governamentais, conscientemente planejadas por atores políticos auto interessados.

Por outro lado, também é possível compreender o Mercosul por uma abordagem do ciclo de uma política pública. A virtude desse modelo consiste em sua capacidade de rastrear os passos percorridos por uma política pública, considerando suas etapas, que segundo Conde (2012) seriam: (1) indicações gerais sobre análise e suas dimensões, aspectos a considerar sobre, (2) agenda, 
(3) formulação e decisão, (4) implementação e (5) avaliação. Ainda, Condé afirma que esse roteiro não pode ser dado como acabado, mas servem como um balizador para o analista. Para mais, o analista em políticas públicas deve considerar que nem sempre as etapas desse ciclo ocorrem simultaneamente. A figura abaixo representa como é pensada a "trilha" a ser percorrida pela abordagem do ciclo de políticas públicas.

Figura 1. Diagramando um esquema analítico Geral

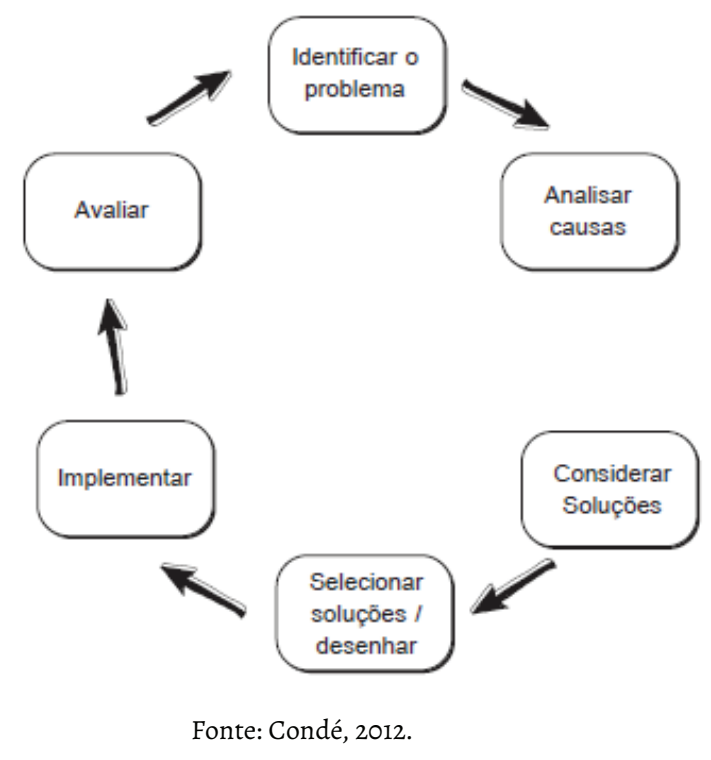

O Mercosul traz em sua própria trajetória histórica o exemplo de quebra desse ciclo. Suas idas e vindas mostram como algumas etapas ocorrem independentemente de outras, onde implementações de políticas públicas, como os acordos bilaterais entre Argentina e Brasil ou Argentina e Paraguai, por exemplo, acabam desencadeando um processo de spillover, configurando uma nova agenda para esse Mercado Comum.

\section{A AGENDA DA INTEGRAÇÃO}

A agenda de integração não se restringe aos países do Cone Sul propriamente. Suas primeiras iniciativas giram em torno de um Mercado Comum latino americano, cujas normas começaram a ser elaboradas pelo Grupo de Trabalho do Mercado Regional em sintonia com a secretaria da CEPAL ainda na década de 50. A integração dos mercados regionais não era um fim em si, mas uma estratégia de acentuar o desenvolvimento da região.

Na realidade, o mercado comum corresponde ao empenho em criar uma nova modalidade para um intercâmbio latino-americano adequado a suas 
grandes exigências: a da industrialização e a de atenuar a vulnerabilidade externa desses países (CEPAL, 2000, p.352).

A integração regional era considerada uma estratégia desenvolvimentista que visava um maior trafego de produtos e bens intra-bloco para diminuir a dependência econômica dos países latinos das potências mundiais (Estados Unidos e Inglaterra). Anexada a essa integração estava uma política de substituição de importações e políticas protecionistas ao mercado interno.

Esse mercado, [...], permitirá realizar racionalmente, através de uma especialização interlatino-americana adequada, a política de substituição de importações provenientes do resto do mundo, a fim de enfrentar esse crescimento lento das exportações primárias (ibid.).

Embora essa agenda desenvolvimentista estivesse em evidência naquele período, dadas as assimetrias existentes entre os países latino americanos, é de se suspeitar que os interesses em questão na integração para um Mercado Comum fossem os mesmos, ou seja, restritos ao campo econômico.

Com relação ao Mercosul, segundo Silva (2006), não é possível encontrarmos uma agenda única ou central que unisse todos os quatro países. A divergência maior pode ser notada entre os dois principais países do bloco, Argentina e Brasil. Enquanto, segundo a autora, a Argentina visava precisamente os ganhos econômicos provenientes da aproximação com o grande mercado brasileiro, a participação do Brasil no bloco tinha como grande interesse seu posicionamento na política internacional enquanto um global player.

Sendo o interesse brasileiro pelo sistema predominantemente político, enquanto o argentino é predominantemente econômico, tal fato suscita a tendência de o Brasil ser mais complacente com as demandas econômicas da Argentina, em troca do apoio político desta, do que reciprocamente a Argentina para com os interesses econômicos brasileiros (JAGUARIBE in SOUSA, 2000, p.55).

Essa complacência pode ser observada com as permissões que o Brasil cedia à Argentina nas adoções de medidas para conter a entrada de produtos brasileiros no país (principalmente de linha branca $^{6}$ ), além de recusar seguir normas comerciais acordadas.

É importante destacar que a agenda da integração do MERCOSUL não foi a mesma ao longo da história. Destacam-se as diferentes posições dos governos brasileiro e argentino em relação à integração regional. De Sarney a Lula é possível verificar diferentes posturas estratégicas. Dentre elas, algumas que

Eletrodomésticos como geladeira, micro-ondas, freezer, fogão. 
aproximam o país das relações comerciais com os Estados Unidos (Collor, por exemplo) em prol do maior aprofundamento das relações comerciais na região, outras que, de certa forma não afastam o Brasil das relações com os Estados Unidos, mas que adota uma "autonomia pela distância" (FONSECA JR., 1998 in SILVA, 2006). Apesar de Fernando Henrique Cardoso ser historicamente reconhecido por suas fortes relações com as políticas e estratégias econômicas que vinham de Washington (neoliberais), demonstrou preocupação com a estrutura institucional do Mercosul, tendo no ano 2000 o "relançamento" deste Mercado, propondo uma retomada da agenda da integração, que na prática não se obteve muitas respostas práticas. Com Lula, a estratégia de fortalecer o Brasil como global player era a marca de sua política externa. Desde que assumiu seu mandato, visitou vários países, dos quais resultaram acordos bilaterais. Sua preocupação maior era com a participação do Brasil nos fóruns do G-8 (em Davos), a composição do Brasil no comitê de segurança da ONU e com a integração dos BRICS.

Esperava-se que com a eleição de Lula e Kirchner, respectivamente, acentuaria as relações locais. Contudo, nenhum avanço importante foi realizado na área, e as promessas de integração não passaram de retóricas.

Outro elemento importante para a composição do Mercosul e sua "estabilidade" (estagnação) é o fracasso da política norte-americana em estreitar os laços econômicos com os países do Sul. A Argentina, diante de sua frágil situação econômica, se posicionava entre o Mercado Comum do Sul e laços econômicos com os Estados Unidos. Impossibilitada sua adesão a este bloco norte-americano diante dos incrementos comerciais no Mercosul, a Argentina se posiciona enquanto um double standing - entre a ALCA e o MERCOSUL. Os Estados Unidos não conseguem aprofundar suas relações com os países do Sul devido ao fracasso no Congresso dos Estados Unidos do fast track. Além disso, a agenda nacional e internacional do governo Bush era marcada, primeiro pelas duvidas e desconfianças com relação ao seu mandato e, por outro lado, uma política externa voltada para o combate ao terrorismo (Guerra ao Terror).

\section{A ESTRUTURA INSTITUCIONAL (FORMULAÇÃO E IMPLEMENTAÇÃO)}

Segundo Arcuri (2007), a estrutura institucional do Mercosul foi definida através do Protocolo de Ouro Preto (POP) de 1994, que compunha:

a. Conselho Mercado Comum (CMC): órgão decisório máximo que era composto pelos Ministros das Relações Exteriores e Ministros da Fazenda, além de outros Ministros convocados quando o tema de discussão tinha afinidade com suas respectivas áreas;

84 / Prelúdios, Salvador, v. 8, n. 8 p. 77-91, jul./dez. 2019 
b. Grupo Mercado Comum (GMC): órgão executivo, com capacidade decisória definida ou delegada pelo CMC. Composto por Coordenadores Nacionais para o Mercosul indicado dentre os quatro da chancelarias, e por outros três funcionários de nível equivalente ao dos Ministérios da Economia, Indústria e Bancos Centrais.

c. Comissão de Comércio do Mercosul (CCM): órgão responsável pelo acompanhamento da aplicação da Política Comercial Comum, da Tarifa Externa Comum, ou das questões derivadas ou correlatas, além de intervir nas fases iniciais de controvérsias entre os Estados-Partes. Composta por funcionários diplomáticos do nível de Diretor de Departamento e seus equivalentes dos Ministérios envolvidos.

Além desses três órgãos centrais, existe um conjunto de órgãos menores composto por reuniões de ministros, reuniões envolvendo especialistas em determinados assuntos, subgrupos de trabalhos, grupos ad hoc, entre outros grupos de alto nível que preparavam os temas que seguem para decisões do GMC e CMC. A esse conjunto agregava-se uma Secretaria Administrativa, uma Comissão Parlamentar Conjunta, um órgão de representação da sociedade civil e o Fórum Consultivo Econômico e Social (FCES) (ibid).

A institucionalidade do Mercosul é um processo inacabado. Reformas e refundações ocorreram desde 1991. Contudo, segundo Arcuri (ibid), o processo de proposição de novas "arquiteturas institucionais" não é suficiente para que os impasses reais sejam superados.

Arcuri aponta duas fases pelas quais o Mercosul deveria percorrer para superar seus problemas internos. A primeira fase consiste em aumentar a confiança mútua e concluir a experiência intergovernamental. Outro ponto seria criar uma estrutura decisória permanente. A segunda fase consiste em criar uma Secretaria Geral do Mercosul, o Parlamento do Mercosul, o Foro Consultivo Econômico e Social (FCES) e um Tribunal de Revisão.

Embora o Tribunal de Revisão exista, ele não possui autonomia orçamentária, proveniente de um orçamento comum do Mercosul. Outra questão que deva ser tratada é a compatibilidade dos julgamentos do Tribunal com os sistemas nacionais (legais).

\section{ASSIMETRIAS E SOBERANIA}

Por assimetrias o artigo se refere às diferenças estruturais da economia dos Estados-membros do Mercosul. Tais assimetrias são responsáveis por alguns desencontros sobre acordos sobre uma política econômica comum, uma vez que o processo de integração leva necessariamente a descoberta de áreas 
sensíveis e de temas em relação aos quais as posições conjuntas são menos fáceis de ser conseguidas (BAUMANN, 2001).

Dadas às assimetrias, o tempo para se adequarem as novas normas comerciais eram equacionadas de forma particular para cada país. Além do mais, os acordos sobre questões comerciais não tinham um caráter de generalidade, ou seja, um acordo tarifário não cobriria todas as áreas (automobilística, açúcar, tecnologia, etc.) da mesma maneira. Ao contrário disso, os acordos eram realizados por meio de setores.

A estrutura brasileira tinha alíquotas baixas para matérias-primas e produtos agrícolas (o a 10\%), tarifas médias ou altas para insumos industriais (10 a $20 \%$ ), e tarifas altas produtos de consumo final (aproximadamente $20 \%$ ). Na Argentina, os insumos industriais tinham as alíquotas mais baixas e, nos setores de bens de capital e informática, a alíquota era zero. O Paraguai tinha tarifa baixa para a maior parte dos produtos e o Uruguai tinha tarifas altas para produtos agrícolas e baixas para insumos agrícolas e industriais. (BAUMANN, 2001, p.29).

Tais assimetrias são consideradas quando os acordos são arquitetados. Acontece que em alguns casos as metas acordadas não são alcançadas pelos países, tendo em vista seus próprios interesses. Dessa forma, com a ausência de uma instituição supranacional que coordene esse processo com autoridade, não é possível solucionar impasses em que as partes não alcancem um consenso.

Contudo, para uma eficácia dessa instituição supranacional, é preciso que se mude a constituição de países como Brasil, cujo mecanismo legal não aplica automaticamente decisões internacionais.

A criação de um órgão supranacional forte e eficiente implica, ainda, outra questão importantíssima: a entrega da soberania nacional (ou parte dela). Este, pelo que podemos observar, não é o desejo do Brasil, uma vez que consideramos sua participação no Mercosul motivada por anseios mais político do que econômicos stricto sensu. Sendo a preocupação central do Brasil sua posição enquanto uma liderança regional que alavanque sua posição de global player diante dos órgãos internacionais, não há um horizonte de transferência da autonomia política que afete sua soberania.

Na fala do Ministro das Relações Exteriores, Luiz Felipe Palmeira Lampreia $^{7}$ (1999 in SILVA, 2006), pode-se observar claramente a posição do ministro em relação a essa questão:

O Brasil não tem razão nenhuma para abrir mão de sua autonomia. Não conheço ninguém de responsabilidade, no Brasil, que pudesse aceitar

Ministro das Relações Exteriores entre 1995 a 2001. 
a ideia de que o governo brasileiro subscrevesse um tratado no qual delegasse a uma pessoa ou a um colegiado, por mais qualificados que fossem, a capacidade de representar, negociar e impor normas para todos os Estados-membros do Mercosul.

Creio que seria inaceitável, para o Congresso Nacional, para a opinião pública brasileira, para a imprensa brasileira, que houvesse uma renúncia de soberania brasileira desta magnitude. ${ }^{8}$

Diante desse quadro e tomando o Estado enquanto ente auto interessado, cujas ações são estrategicamente orientadas visando benefícios (profits) ${ }^{9}$, o dilema do Mercosul se converte basicamente num dilema de ação coletiva, que pode, em tese, ser resolvido pela lógica Hobbesiana: se a natureza dos Estados é marcada pelo auto interesse, e sendo o cenário da integração regional caracterizado por uma anarquia política ${ }^{10}$ cujo locus de atuação apresenta recursos escassos, a saída plausível seria a instituição de um "governo soberano".

A saída pela delegação da soberania se torna a solução mais plausível para a implantação de um Mercado Comum do Sul tendo em vista que, diante das experiências históricas, os processos de "reformulação" e "refundação" da arquitetura institucional não gerou um efeito de spillover satisfatório. Por mais que a institucionalidade do Mercosul tenha possibilitado avanços nas relações entre os países, a natureza dessas instituições não criaram o cenário possível para a completa integração.

\section{EFEITOS ECONÔMICOS DA INTEGRAÇÃO REGIONAL}

Através de uma política de integração de mercado, espera-se que as relações comerciais entre os Estados-membros se intensifiquem cada vez mais ao longo dos anos, ou seja, que através da livre circulação de mercadorias possam-se substituir as importações de países como Estados Unidos e do bloco UE, privilegiando as trocas comerciais regionais. Analisemos as quatro tabelas abaixo, referentes às exportações e importações dos dois maiores países do bloco (Argentina e Brasil):

Conferência realizada para os Conselheiros do Centro Brasileiro de Relações Internacionais.

Podemos considerar a palavra "lucro", também.

10 Falta de um governo superior aos Esatdos-membros. 
Tabela 1. Exportações do Brasil por países parceiros.

\begin{tabular}{l|c|c|c|c|c|c|c|c|c|c}
\hline \multicolumn{10}{c}{ Brazil, Export by Partner (\%) } \\
\hline Partner/Year & $\mathbf{2 0 1 4}$ & $\mathbf{2 0 1 3}$ & $\mathbf{2 0 1 2}$ & $\mathbf{2 0 1 1}$ & $\mathbf{2 0 1 0}$ & $\mathbf{2 0 0 9}$ & $\mathbf{2 0 0 8}$ & $\mathbf{2 0 0 7}$ & $\mathbf{2 0 0 6}$ & $\mathbf{2 0 0 5}$ \\
\hline China & 18,4 & 19,1 & 17 & 17,31 & 15,58 & 13,2 & 8,29 & 6,69 & 6,1 & 5,77 \\
\hline U.S & 12,06 & 10,27 & 11,07 & 10,13 & 9,75 & 10,29 & 14,01 & 15,77 & 17,98 & 19,24 \\
\hline Argentina & 6,39 & 8,1 & 7,42 & 8,87 & 9,34 & 8,36 & 8,89 & 8,97 & 8,52 & 8,38 \\
\hline Paraguay & 1,42 & 1,24 & 1,08 & 1,16 & 1,29 & 1,1 & 1,26 & 1,03 & 0,9 & 0,81 \\
\hline Uruguay & 1,31 & 0,86 & 0,9 & 0,85 & 0,77 & 0,89 & 0,83 & 0,8 & 0,73 & 0,72 \\
\hline
\end{tabular}

Fonte: http://wits.worldbank.org/country-analysis-visualization.html

Tabela 2. Exportações da Argentina por países parceiros.

\begin{tabular}{l|c|c|c|c|c|c|c|c|c|c}
\hline \multicolumn{10}{c}{ Argentina, Export by Partner (\%) } \\
\hline Partner/Year & $\mathbf{2 0 1 4}$ & $\mathbf{2 0 1 3}$ & $\mathbf{2 0 1 2}$ & $\mathbf{2 0 1 1}$ & $\mathbf{2 0 1 0}$ & $\mathbf{2 0 0 9}$ & $\mathbf{2 0 0 8}$ & $\mathbf{2 0 0 7}$ & $\mathbf{2 0 0 6}$ & $\mathbf{2 0 0 5}$ \\
\hline China & 6,53 & 7,19 & 6,20 & $\mathbf{7 , 4 1}$ & 8,50 & 6,59 & 9,08 & 9,26 & 7,47 & 7,86 \\
\hline U.S & 5,91 & 5,60 & 5,11 & 5,12 & 5,38 & 6,61 & 7,71 & 7,79 & 8,85 & 11,40 \\
\hline Brazil & 20,31 & 21,16 & 20,38 & 20,64 & 21,15 & 20,44 & 18,96 & 18,80 & 17,49 & 15,78 \\
\hline Paraguay & 1,78 & 1,69 & 1,69 & 1,63 & 1,69 & 1,52 & 1,55 & 1,40 & 1,34 & 1,27 \\
\hline Uruguay & 2,29 & 2,33 & 2,45 & 2,37 & 2,28 & 2,89 & 2,57 & 2,16 & 2,58 & 2,15 \\
\hline
\end{tabular}

Fonte: http://wits.worldbank.org/country-analysis-visualization.html

Tabela 3. Importações do Brasil por países parceiros.

\begin{tabular}{l|c|c|c|c|c|c|c|c|c|c}
\hline \multicolumn{10}{c}{ Brazil, Import by Partner (\%) } \\
\hline Partner/Year & $\mathbf{2 0 1 4}$ & $\mathbf{2 0 1 3}$ & $\mathbf{2 0 1 2}$ & $\mathbf{2 0 1 1}$ & $\mathbf{2 0 1 0}$ & $\mathbf{2 0 0 9}$ & $\mathbf{2 0 0 8}$ & $\mathbf{2 0 0 7}$ & $\mathbf{2 0 0 6}$ & $\mathbf{2 0 0 5}$ \\
\hline China & 16,3 & 15,57 & 15,35 & 14,49 & 15,15 & 12,46 & 11,57 & 10,46 & 8,75 & 7,28 \\
\hline U.S & 15,41 & 15,14 & 14,61 & 15,13 & 15,07 & 15,84 & 14,93 & 15,66 & 16,26 & 17,47 \\
\hline Argentina & 6,17 & 6,87 & 7,37 & 4,47 & 7,99 & 8,84 & 7,65 & 8,63 & 8,82 & 8,48 \\
\hline Paraguay & 0,53 & 0,43 & 0,44 & 0,32 & 0,34 & 0,46 & 0,38 & 0,36 & 0,32 & 0,43 \\
\hline Uruguay & 0,84 & 0,74 & 0,82 & 0,77 & 0,87 & 0,97 & 0,59 & 0,65 & 0,68 & 0,67 \\
\hline
\end{tabular}

Fonte: http://wits.worldbank.org/country-analysis-visualization.html

Tabela 4. Importações da Argentina por países parceiros.

\begin{tabular}{l|c|c|c|c|c|c|c|c|c|c}
\hline \multicolumn{10}{c}{ Argentina, Import by Partner (\%) } \\
\hline Partner/Year & $\mathbf{2 0 1 4}$ & $\mathbf{2 0 1 3}$ & $\mathbf{2 0 1 2}$ & $\mathbf{2 0 1 1}$ & $\mathbf{2 0 1 0}$ & $\mathbf{2 0 0 9}$ & $\mathbf{2 0 0 8}$ & $\mathbf{2 0 0 7}$ & $\mathbf{2 0 0 6}$ & $\mathbf{2 0 0 5}$ \\
\hline China & 16,39 & 15,36 & 14,53 & 14,23 & 13,47 & 12,43 & 12,36 & 11,39 & 9,14 & 5,33 \\
\hline U.S & 13,52 & 10,95 & 12,39 & 10,47 & 10,79 & 13,33 & 12,55 & 11,95 & 12,57 & 15,8 \\
\hline Brazil & 21,75 & 26,01 & 26,14 & 29,85 & 34,6 & 30,47 & 31,28 & 32,79 & 34,76 & 37,04 \\
\hline
\end{tabular}




\begin{tabular}{l|l|l|l|l|l|l|l|l|l|l}
\hline Paraguay & 0,75 & 0,72 & 0,69 & 0,69 & 0,77 & 1,8 & 3,1 & 2,36 & 1,48 & 1,59 \\
\hline Uruguay & 0,69 & 0,68 & 0,76 & 0,82 & 1,03 & 0,9 & 0,94 & 1,05 & 0,91 & 1,95 \\
\hline
\end{tabular}
Fonte: http://wits.worldbank.org/country-analysis-visualization.html

Observando os dados, com relação às exportações tendo como origem Argentina e Brasil é possível caracterizar dois quadros bem distintos: 1) o Brasil é o principal destinatário das exportações Argentinas, cujas taxas são muito superiores aos demais países e 1.1) essas exportações vem se intensificando ao longo dos últimos dez anos; 2) o Brasil possui como principais compradores de seus produtos países como China e Estados Unidos, com taxas que equivalem quase o dobro ou o triplo das exportações para a Argentina e 2.1) as exportações do Brasil para Argentina apresentou uma relativa queda comparando os anos de 2005 e 2014.

No que diz respeito às importações percebe-se que: 1) as principais importações da Argentina têm como origem o Brasil e 1.1) as importações deste país, apesar de diminuírem consideravelmente, ainda se mantêm como a principal daquele país; 2) O Brasil tem suas importações decorrentes de países como China e Estados Unidos e 2.1.) As taxas de importação da Argentina diminuíram comparado os anos 2005 a 2014.

Os gráficos abaixo representam a relação entre Argentina e Brasil em relação às importações e exportações entre ambos os países entre os anos de 2005 e 2014. Vejamos:

Gráfico 1. Exportações entre Argentina e Brasil (2005-2014)

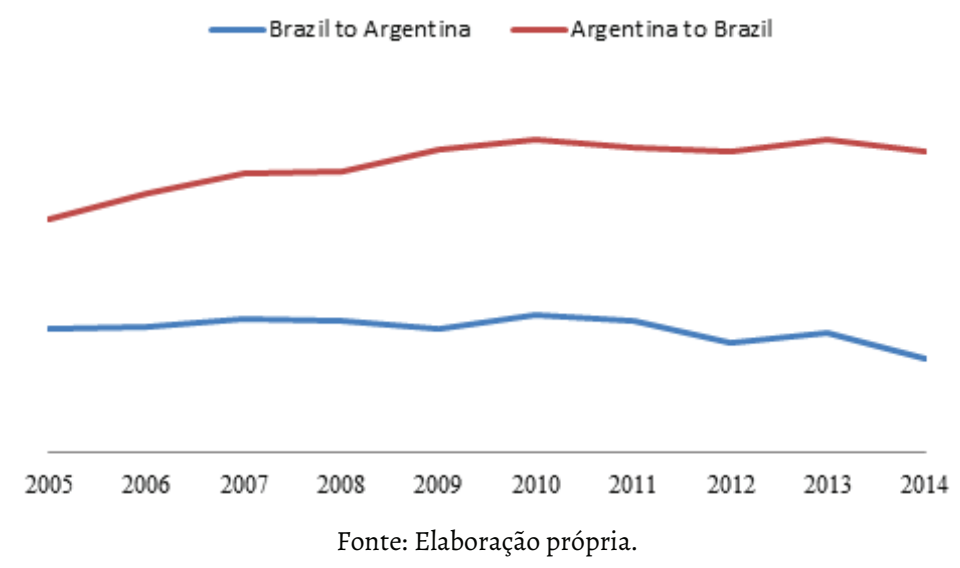


Gráfico 2. Importações entre Argentina e Brasil (2005-2014)
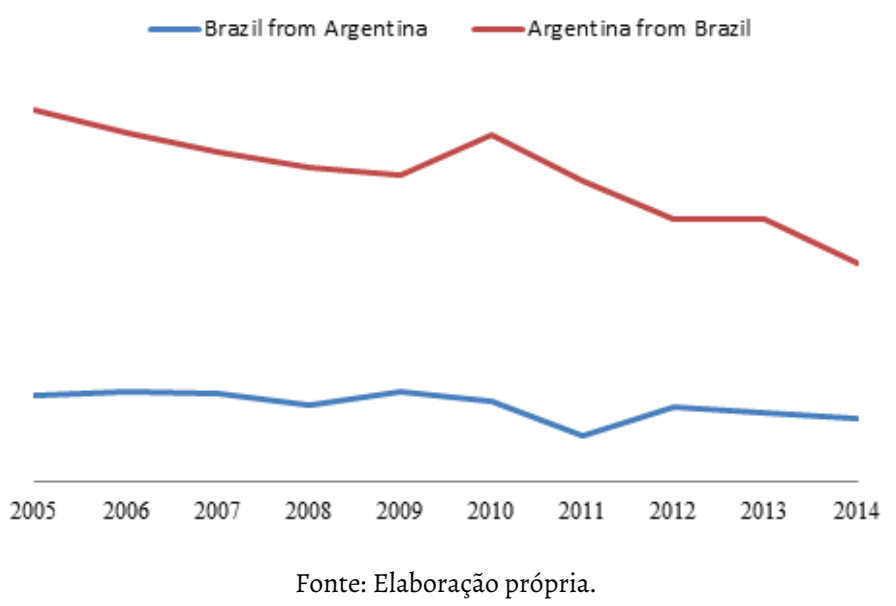

A análise desses dados nos permite concluir que o Brasil possui uma estratégia econômica muito mais independente e diversificada com relação aos países do Sul do que a Argentina, o que reforça a hipótese (levantada no início do artigo) de que a participação do Brasil nesse bloco regional é motivada muito mais por aspectos políticos do que econômicos, em oposição à Argentina, que possui uma relação mais estreita com o Brasil.

Em outras experiências de integração econômica, como o NAFTA, por exemplo, podemos observar que há uma maior correspondência econômica entre Estados Unidos, México e Canadá (Estados-membros). Em 2014, 76,81\% das exportações do Canadá se dirigiram aos Estados Unidos. O México, por sua vez, apresentou uma taxa de $80,30 \%$ de suas exportações para os Estados Unidos ${ }^{11}$.

\section{CONCLUSÃO: À GUISA DE UMA AVALIAÇÃO.}

Diante dos dados acima, conclui-se que embora as relações econômicas entre os países do Mercosul tenham se intensificado desde sua criação em 1991 (SILVA, 2006), os dez últimos anos têm demonstrado que a estratégia econômica adotada pelos Estados-membros não tem cooperado com o avanço da integração regional. Destaca-se aí a figura do Brasil. Uma vez que ocupa a posição de liderança regional, cuja economia se mostra muito mais "descolada" do que as outras, a vontade de aprofundar a integração depende muito mais dele do que dos outros países.

Por outro lado, o Brasil tem se mostrado, principalmente no governo Lula, mais disposto a acordos bilaterais (com a China no âmbito econômico) e com o BRICS (contemplando aspectos mais políticos como a reforma do Conselho de Segurança da ONU e as reuniões do G20).

I1 Fonte: http://wits.worldbank.org/country-analysis-visualization.html. 
Enquanto global player, o interesse do Brasil é muito mais por manter acordos econômicos com relação à união aduaneira do que aprofundar as raízes de um Mercado Comum, uma vez que isso demandaria entrega parcial de soberania para instituições supranacionais, o que sem sombra de dúvidas levaria qualquer governo nacional ao desgaste político interno.

Essa conjuntura, marcada pela "imobilidade" do mercado comum, só foi possível graças ao fracasso de uma política norte-americana (fast tracks). Caso a Casa Branca tivesse ganhado o aval do Capitólio para efetuar suas políticas econômicas (fast track), o Brasil se encontraria diante de um desafio que prejudicaria sua soberania na América do Sul, criando dificuldade para este se lançar enquanto global player.

Essa conjuntura forneceu ao Brasil certa estabilidade enquanto liderança local, permitindo a ele caminhar a passos curtos com o projeto Mercosul e empreender outras políticas públicas internacionais em outros blocos.

\section{REFERÊNCIAS BIBLIOGRÁFICAS}

ARCURI, R. B. (2007). Mercosul e o desafio da operacionalidade: gerando resultados para a integração. Rio de Janeiro: CEBRI.

BAUMANN, R. (org.) (2001). Mercosul: Avanços e Desafios da Integração. Brasília: IPEA/CEPAL.

BIELSHOWSKY, R. (org.) (2000). Cinquenta anos de pensamento na CEPAL. Rio de Janeiro: Record.

CONDÉ, E. S. (2012) Abrindo a Caixa: dimensões e desafios nas análises de políticas públicas. E.ducação. v.2.n.2.

DYE, T. (2009). Understanding Public Policy. 13.ed. New York: Longman.

SILVA, L. T. (2006). Política Externa Brasileira para o Mercosul: interesses estratégicos e crise da integração regional. 107 p. Dissertação. USP. 
